\title{
HAS NOZICK JUSTIFIED THE STATE?
}

BY

\author{
CHARLES SAYWARD AND WAYNE WASSERMAN
}

\begin{abstract}
$I_{N}$ Anarchy State and Utopia (Basic Books, 1974)
Robert Nozick states that "The fundamental question of political philosophy, one that precedes questions about how the state should be organized, is whether there should be any state at all" (p. 4). In Part I of his book he attempts to justify the state. We argue that he is not successful.
\end{abstract}

Here is Nozick's overall strategy: He first focuses upon anarchic situations in which people "generally satisfy moral constraints and generally act as they ought" (p. 5). He then claims that:

If one could show that the state would be superior even to this most favored situation of anarchy, the best that realistically can be hoped for, or would arise by a process involving no morally impermissible steps or would be an improvement if it arose, this would provide a rationale for the state's existence; it would justify the state. (p. 5; italics added.)

Nozick thus claims that satisfying the second disjunct is sufficient to justify the state and proceeds to argue that the second condition obtains.

Unfortunately there is much that is objectionable in all this. We do not think the second condition, even if it obtains, justifies the state. We briefly address this matter in the final section of our paper. More seriously, perhaps, it is not at all clear what Nozick is trying to do when he attempts to show that the second sufficient condition obtains. What, for example, does Nozick mean by 'arises' when he says, "Our argument detailing how a minimal state arises, legitimately, from a state of nature is now completed" (p. 120)? Not 'actually arises' because a state of nature is a counterfactual situation. He must mean either 'could arise' or 'would arise'. But which? In Section II of this paper we consider various ways of construing Nozick's words and argue that on each such construal he faces serious difficulties.

On one interpretation which has some textual support, Nozick's attempt to show that the second sufficient condition for justifying the state obtains amounts to arguing for the following conditional: 
(A) If there were a state of nature in which people generally satisfied moral constraints and generally acted as they ought ('a favored state of nature' for short), then a minimal state could arise in a series of morally permissible steps.

If it is (A) he is arguing for, then he must be taking the anarchist to be asserting this:

(B) If there were a favored state of nature, no state would arise out of it in a series of morally permissible steps.

One has to ask: What anarchists do you (Nozick) have in mind? Who is going to assert (B)? Nothing like the effort Nozick exerts, after all, is required to falsify (B).

Consider for example the following story or possible world: There is a favored state of nature in which all persons read Hobbes. Convinced of the desirability of the state by Hobbes' powerful prose they unanimously agree to form a state and to accept its justice.

That (B) can be refuted in such a trivial manner shows that were Nozick arguing against $(B)$ he would have misconstrued his project. Establishing the falsity of (B) would hardly count as justifying the state. To do that requires refuting an interesting thesis.

There is good reason to take Nozick to be arguing for a conditional sentence with a 'would' consequent, not for any sentence with a 'could' consequent. First, in key passages he employs the word 'would' (See, e.g., pp. 5, 17, 114). Second, in many passages he speaks of what will happen, not what might happen. This choice of words in context suggests to us he is working in a 'would' not a 'could' modality. Finally, Nozick himself comments upon the inadequacy of merely establishing that a state could so arise (p. 119). So here is a reading of Nozick with considerable textual support:

(C) If there were a favored state of nature, a state would arise out of it in a series of morally permissible steps.

Nozick sets out a series of supposedly morally permissible steps by which the state's emergence would take place: (1) Out of enlightened self-interest people in the state of nature will form mutual protective associations. (2) Professionals will then be hired to fill this role (p. 13). (3) Within a given geographic unit there would arise a dominant protective association (p. 16-17). The dominant protective association is not a state; for a state ascribes to itself the role of sole legitimate dispenser of enforced justice; and:

The protective associations . . . do not make such an announcement . . Nor does it seem morally legitimate for them to do so. So the system of private protective associations, if they perform no morally illegitimate action, appears to lack any monopoly element and so appears not to constitute or contain a state (p. 24).

(4) The state emerges out of the dominant protective association in this way: Within the geographical unit there will exist the clients of the dominant protective 
association and nonclients (which Nozick calls 'independents'). What happens when an independent attempts to exact compensation from a client for an alleged crime? Nozick considers two possibilities:

... one might punish them [independents] for their misenforcements of their rights of retaliation, punishment and exaction of compensation. An independent would be allowed to proceed to enforce his rights as he sees them and as he sees the facts of his situation; afterwards the members of the protective association would check to see whether he had acted wrongly or overacted. If and only if he had done so, would they punish him or abstract compensation from him.

But the victims of the independent's wrongful and unjust retaliation may be not only damaged but seriously injured and perhaps even killed. Must one wait to act until afterwards? Surely there would be some probability of the independent's misenforcing his rights, which is high enough (though less than unity) to justify the protective association in stopping him until it determines whether his rights indeed were violated by its client. Wouldn't this be a legitimate way to defend their clients? Won't people choose to do business only with agencies that offer their clients protection, by announcing they will punish anyone who punishes a client without first using some particular sort of procedure to establish his right to do so, independently of whether it turns out that he could have established this right? (pp. 55-56).

The move to the state could be resisted, independents could be allowed to enforce their rights, and be forced to compensate for errors. But this would force clients to face risks, and the clients would require their protective association to prevent these dangerous enforcements. The move is not resisted.

(5) A state has arisen. However, for this last step to occur in a morally permissible fashion the dominant protective association must treat non-clients so prevented from self-enforcement in a way described by the following passage:

If the agency knows that [the would-be self-enforcing non-client] has used a reliable procedure, it accepts its verdict of guilty, and it cannot intervene on the assumption that its client is, or well might be, innocent. If the agency deems the procedure unreliable or doesn't know how reliable it is, it need not presume its client guilty, and it may investigate the matter itself. If upon investigation it determines that its client is guilty, it allows him to be punished. ... It would seem that the protective agency does have to pay compensation to users of relatively unreliable procedures for any disadvantages caused by the enforced delay; and to the users of procedures of unknown reliability it must pay full compensation if the procedures are reliable, otherwise compensation for disadvantages (p. 104).

While considerable thought could be devoted to determining just what such an agency must do in order to avoid violating rights, we can see that Nozick is committed to something like this: If the dominant protective association forced independents to accept its procedures of justice, then that association would take required steps, including compensation, needed to ensure that in so forcing independents it does not violate their rights.

Thus, to justify (C) Nozick must justify the following series of counterfactuals:

(D) If there were a favored state of nature, mutual protection associations would arise. 
(E) If there were a favored state of nature in which mutual protection associations arise, a dominant protective association would arise.

(F) If there were a dominant protective association arising in a favored state of nature, that association would force independents to accept the association's procedures of justice.

(G) If there were a dominant protective association arising in a favored state of nature and it forced independents to accept the association's procedures of justice, then the association would take all required steps, including the payment of compensation, needed to ensure that in so forcing the independents it does not violate their rights.

Early in his book Nozick rejects investigating the anarchic situation which would exist if the actual political situation did not exist, partially because of the "enormous unmanageability of pursuing that counterfactual to arrive at a particular situation" (p. 4). Why does he think that (D) through (G) are any more manageable?

In order for a particular counterfactual to be manageable (i.e. in order for its truth-value to be ascertainable) there must exist well-confirmed generalizations governing relevant subject matter. For example, we know 'If Armstrong had been left on the moon without a space suit, he would have died shortly thereafter' to be true because of various highly confirmed generalizations which can be made about the human body and the moon. To justify a particular counterfactual it is necessary to produce the relevant generalizations and their evidence. Nozick has not produced generalizations about human behavior which justify (D) through (G). Nor does he or anyone else seem to be able to do so. In sort, the counterfactual assertions do not seem to be adequately grounded in fact.

Although Nozick does not seem to fully appreciate this problem, he does respond to a related objection, which comes to this: If persons in the favored state of nature have certain types of motivations, a state would not arise. For example, were everyone in the state of nature a confirmed anarchist or pacifist the state might not emerge. Thus, the objection continues, (C) would not be true. Nozick responds:

[It] must be admitted that other individuals with special motivations would not behave as we have described: for example, people whose religion prohibits purchasing protection or joining with others in protective ventures; or misanthropes who refuse to cooperate with or hire any other persons; or personal pacifists who refuse to support or participate in any institution that uses force, even for their own self-defense. We must restrict our claim that a state would arise from a state of nature, so as to exclude these special psychologies which thwart the operation of the invisible-hand process we have described. For each special psychology, we may insert a specific clause in the claim to exclude it. Thus: in a territory containing rational individuals who also are willing to use force in self-defense and are willing to cooperate with others and to hire them, ... (p. 131)

So we have a third interpretation of Nozick's thesis:

(H) If there were a state of nature in a territory containing rational individuals who also are willing to use force in self-defense and are willing to cooperate with others and to hire them . . ., then a minimal state would arise in a morally permissible way. 
One simple problem with $(\mathrm{H})$ is that it is not a statement. To convert it to a statement one has to fill in the blank, and until this is done $(\mathrm{H})$ cannot be used to justify anything.

While Nozick doesn't fill in the blank, his comments (pp. 130-131) suggest a recipe for filling in the blank: add to the antecedent of $(\mathrm{H})$ clauses which eliminate factors that countervail against $(\mathrm{C})$ or any of its supporting counterfactuals (e.g. (D)-(G) ). Unfortunately, even if this procedure can be used to obtain an adequately supported counterfactual of the desired sort (and we are not sure it can be) it is not clear how such a statement could be used to justify the state. An anarchist, after all, could use a similar strategy to obtain a counterfactual whose consequent is the denial of that in $(\mathrm{H})$. Which counterfactual should we pay attention to?

\section{III}

In setting out Nozick's basic strategy we saw that he thinks that a sufficient condition for justifying the state is to show how a state arises in a morally permissible way from a state of nature. We have seen that the content of this allegedly sufficient condition is obscure and that difficulties arise for each interpretation considered. We do admit that there may be an interpretation which is not subject to such difficulties. But even if such an interpretation could be produced there would still be reason to doubt that the state had been justified. The fact is that one situation might arise out of a second in a morally permissible way and still be morally inferior to the second. For example, as far as we know Nixon first became President of the United States in a morally permissible manner. Yet that alone is hardly grounds for concluding that his tenure as President was morally superior to those of his predecessors.

Central to much, if not all, anarchist thinking is the idea that the state is an evil institution. Nozick responds to this key idea by arguing that the state arises in a morally permissible way. Evidently he assumes that an evil institution cannot so arise. This needs to be argued, not assumed.

Nozick's project rests upon (1) his claim that the state arises from a state of nature in a morally permissible way, and (2) his claims that the truth of (1) justifies the state. Claim (1) awaits clarification. Claim (2) is both unargued and dubious.

The University of Nebraska

Lincoln, Nebraska 